\title{
LOS SEPULCROS DEL CARDENAL FRAY GARCÍA DE LOAYSA Y SUS PADRES EN EL MONASTERIO DOMINICO DE TALAVERA DE LA REINA *
}

\author{
POR \\ JUAN NICOLAU CASTRO \\ Doctor por la Universidad Autónoma de Madrid
}

\begin{abstract}
Se estudian los sepulcros D. Pedro Loaysa y de su esposa Dña. Catalina de Mendoza, así como el de su hijo el Cardenal Fray García de Loaysa. Se conservan en el antiguo monasterio dominico de San Ginés de Talavera de la Reina. Se atribuyen al taller de Bigarny los dos primeros y al de Gregorio Pardo, quizá terminando la obra del padre, el último.
\end{abstract}

Palabras clave: Sepulcros. Escultura S. xvi. Pedro de Loaysa. Catalina de Mendoza. García de Loaysa. Convento de San Ginés.Talavera de la Reina. Bigarny. Gregorio Pardo.

This is a study of the tombs of D. Pedro Loaysa and his wife Dña. Catalina de Mendoza, as well as that of their son, Cardinal Friar García de Loaysa. They are preserved in the old Dominican monastery of San Ginés in Talavera de la Reina. The first two are attributed to the workshop of Bigarny and the third to that of Gregorio Pardo.

Key words: Tombs. Sculpture. Sixteenth century. Pedro de Loaysa. Catalina de Mendoza. García de Loaysa. Convent of San Ginés. Talavera de la Reina. Bigarny. Gregorio Pardo.

El monasterio dominico de San Ginés de Talavera de la Reina fue una víctima más de la desamortización del s. xIx, vendiéndose su edificio, que quedó convertido en fábrica de tinajas. De su antiguo esplendor es poco lo conservado, la arquitectura de la iglesia y el claustro, y de su decoración sólo han permanecido «in situ» los sepulcros de D. Pedro de Loaysa y de su esposa Dña. Catalina de Mendoza, padres del Cardenal Fray Garcia de Loaysa, y la estatua yacente del sepulcro del propio Cardenal que aunque publicados, con antigua fotografía, por el Conde de Cedillo en su Catálogo Monumental de la Provincia de Toledo ', no han tenido mayor eco en la bibliografía artística ${ }^{2}$.

\footnotetext{
* Este trabajo forma parte de un proyecto de investigación financiado por la DGES (PB 98-0708).

I Cedillo, Conde de: Catálogo Monumental de la Provincia de Toledo, Diputación Provincial de Toledo, 1959.

2 Don Ricardo de Orueta, que dedicó una de sus obras al estudio de la escultura funeraria de las provincias de Ciudad Real, Cuenca y Guadalajara, aparecida en 1919, tuvo siempre en proyecto realizar otra segunda obra de las provincias de Toledo y Madrid que nunca llegó a ver la luz. Pero una prueba clara de que estudió estos sepulcros talaveranos es la existencia de unas antiguas fotografías suyas del sepulcro de Dña. Catalina de Mendoza conservadas hoy en la fototeca del Instituto Velázquez. Como un pequeño homenaje a su memoria hemos decidido incluir estas fotografías en nuestro estudio.
} 
El monasterio fue fundado por un curioso personaje, Fray Juan Hurtado, natural de Salamanca, que, como militar, estuvo al servicio de los Reyes Católicos en la guerra de Granada, abandonando después la carrera de las armas por la eclesiástica e ingresando en la orden dominica, donde llegaría a ser prior del famoso convento de San Esteban de Salamanca. Con posterioridad se marcaría una nueva meta, la de fundar monasterios en los que se practicase una rigurosa observancia, lo que le llevaría a Talavera en 1519. Era entonces general de la orden dominica el talaverano Fray Garcia de Loaysa, quien dio su aquiescencia, con agrado, el 2 de enero de dicho año. Éste, que había entrado ya en estrecho contacto con el Emperador, acogió bajo su especial protección el convento talaverano hasta el punto de que, en gran parte de la historiografía tradicional, ha pasado por su verdadero fundador, decidió hacer de la iglesia el lugar de su eterno descanso, enterrándose en él juntamente con sus padres ${ }^{3}$.

Fray García de Loaysa es uno de los personajes del siglo Xvi español que con mayor urgencia están necesitando una extensa y bien documentada biografía ${ }^{4}$. Su poder e influencia fueron muy grandes y su figura con frencuencia controvertida. Fue general de la orden dominica, obispo de Osma y Siguenza, Cardenal de la iglesia de Roma y arzobispo de Sevilla. Intimamente ligado a la persona del Emperador fue nombrado su confesor y se le llenó de honores, encomendándole las más delicadas misiones, primer Presidente del Consejo de Indias, Comisario General de la Cruzada, miembro del Consejo de Estado y un largo etc. Fue muy importante su actuación en la persecución de frailes comuneros y en el proceso de evangelización de América. El nombró y obligó a aceptar el nombramiento de obispo de Chiapas a Fray Bartolomé de las Casas. Acompañó al Emperador a Bolonia a su coronación y permaneció en Roma durante tres años, estrechamente ligado a la persona del papa Clemente VII, donde su persona y su misión merecieron grandes críticas. El Padre Fray Juan de la Cruz, uno de sus primeros biógrafos, resume, acertadamente a nuestro juicio, en una sola frase el verdadero talante de su carácter, dice textualmente, «porque todos o le amaban o le temían por la autoridad que tenía del Emperador y por el valor de su persona» 5 .

Sabemos que el sucesor de Fray Juan Hurtado en el convento de Talavera, Padre Andrés de Pangua, otorgaba escritura de concierto el 16 de diciembre de 1525 ante el escribano de Talavera, Fernando Rur o Ruz, con el «maestro de cantería vizcaino» Juan Martínez de Aguirre para llevar a cabo la obra de la iglesia ${ }^{6}$.

El arquitecto del templo sería el lego dominico Fray Martín de Santiago autor, entre otras muchas obras, de gran parte de la iglesia del convento de San Esteban de Salamanca ${ }^{7}$. Tradicionalmente se viene utilizando como fechas de construcción del monasterio los años 15301536, pero habrá que adelantarse, como hemos visto, a 1525, aunque también es posible se deba separar la construcción del convento y la de su espléndida iglesia.

\footnotetext{
${ }^{3}$ Los datos de la fundación del convento los hemos entresacado fundamentalmente del Libro Becerro del Convento de San Ginés de la Orden de Predicadores de 1520 a 1641 existente en el Archivo Histórico Nacional de Madrid y del Padre Fray Juan de la Cruz en su Crónica de la Orden de Predicadores, de su principio y suceso hasta nuestra edad, T. I, Lisboa, 1567 del ejemplar conservado en la biblioteca de la Real Academia de la Lengua. Otras muchas crónicas de la orden consultadas parecen copiar a ésta, que se escribe muy poco después de la muerte del Cardenal Fray García de Loaysa y por un religioso que moró en la comunidad talaverana.

${ }^{4}$ La bibliografía existente en la actualidad sobre el Cardenal Fray García de Loaysa es muy amplia, sólo queremos dejar aquí constancia de la obra citada del Padre Fray Juan de la Cruz que parece el punto de partida de todas las biografías posteriores, la del Padre Gonzalo de Arriaga, Historia del Colegio de San Gregorio de Valladolid editada en 1928 en Valladolid por el Padre Manuel $\mathrm{M}^{\mathrm{a}}$ Hoyos y la de José $\mathrm{M}^{\mathrm{a}}$ Gómez, Personajes Ilustres de Talavera de la Reina, Talavera, 1999, donde se enumera moderna bibliografía.

5 Padre Fray Juan de la Cruz, o.c., fol. 192.

${ }^{6}$ Libro Berro del Convento de San Ginés..., fol. 7.

7 Fernández Arenas, José: «Martín de Santiago. Noticias de un arquitecto andaluz activo en Salamanca», Boletín del Seminario de Estudios de Arte y Arqueología, Valladolid, 1977, T. XLIII, pp. 157-172.
}

$A E A$, LXXVI, 2003, 303, pp. 267 a 276 

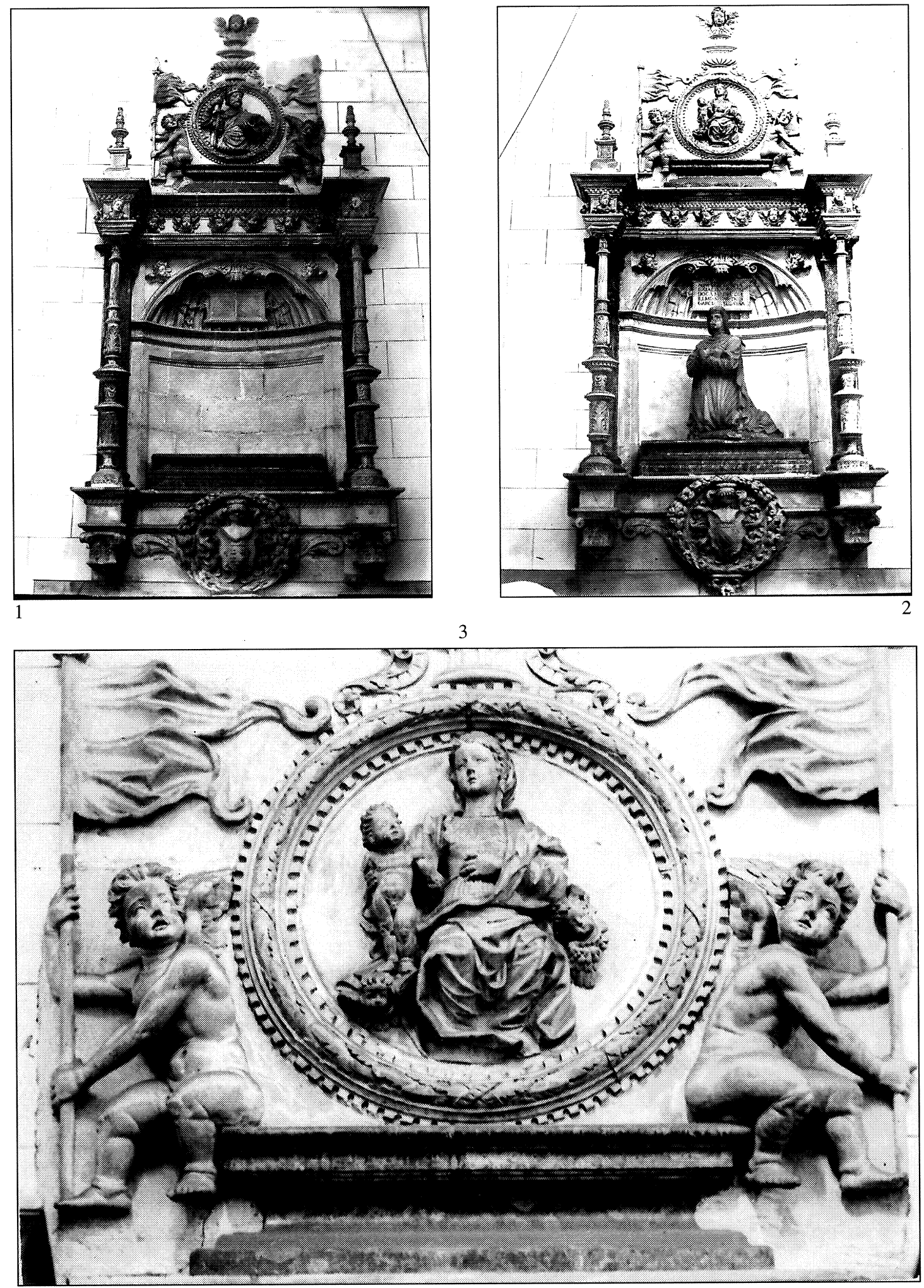

Fig. 1. Sepulcro de don Pedro de Loaysa. Talavera de la Reina. Antigua iglesia de Dominicos.

Figs. 2 y 3. Sepulcro de Doña Catalina de Mendoza (vista general y detalle). Talavera de la Reina. Antigua iglesia de Dominicos.

AEA, LXXVI, 2003, 303, pp. 267 a 276 
La historia del convento talaverano es compleja. Fue un convento vivo y las obras y reformas se sucedieron en él a lo largo de los siglos. Tras el desastre de la francesada y la desamortización, el monasterio fue totalmente modificado en los años finales del siglo XIX para erigir en él el centro de enseñanza religiosa actual ${ }^{8}$. De las obras de arte que allí se atesoraban y de las que nos han llegado una serie de indicios, ya hemos indicado que sólo se han conservado los sepulcros de los Loaysa. Son piezas de la primera mitad del siglo XVI, a todas vistas muy interesantes y que creemos merecen el detenido estudio que pretendemos realizar en este artículo. Desgraciadamente y a pesar de la intensa búsqueda documental que hemos llevado a cabo en archivos de Toledo, Talavera, Madrid y Valladolid, hemos encontrado pocos datos seguros, ya que los protocolos de esas fechas, a los que la investigación nos remitía, se encuentran desaparecidos.

Para el estudio del conjunto tenemos que distinguir entre los sepulcros de los padres y el del propio Cardenal. Los de los padres, colocados en el presbiterio a derecha e izquierda del retablo mayor, siguen el modelo de retablo hornacina tan frecuente en la arquitectura sepulcral del momento. Se veían en ellos, en la hornacina principal, sus esculturas orantes, de las que hoy sólo queda la de la madre, Dña. Catalina de Mendoza, y ha desaparecido la del padre, Don Pedro de Loaysa que, al parcer, aun llegó a ver el historiodor de Talavera D. Ildefonso Fernández y Sánchez en el último tercio del siglo xIX ${ }^{9}$. Según criterio de María José Redondo Cantera, estos sepulcros talaveranos se inspiraron en los de Don Pedro Hurtado de Mendoza y Dña. Juana de Valencia, su esposa, que, procedentes del convento dominico de Santo Domingo de Benalac o Benalaque, hoy se conservan en la parroquia de San Ginés de Guadalajara ${ }^{10}$.

Por datos que conocemos, debieron formar un conjunto homogéneo con el desaparecido retablo mayor de la iglesia en el que pudieron trabajar artistas comunes. Sabemos cómo era el retablo por un manuscrito anónimo, de la segunda mitad del siglo xvIII, que lo describe minuciosamente conservado en la Biblioteca Nacional, en el que incluso aparece un diseño de éste ${ }^{11}$. Estaba formado por tres cuerpos y cinco calles que se alzaban sobre un cuarto cuerpo a modo de predela. La calle central y las dos exteriores estaban flanqueadas por entrecalles con pequeñas figuras de santos. El conjunto se componía de talla y pintura sobre tabla con escenas de la vida de Cristo y de la Virgen. La calle central, la única toda de escultura, estaba presidida, de abajo hacia arriba, por Santo Domingo, San Ginés, titular del convento, la Asunción, el Calvario, y remataba en triángulo o frontón donde estaba pintado el escudo de la orden dominica. La predela se adornaba con esculturas de los doce apóstoles. En el momento de redactarse el manuscrito, el retablo había sufrido algunas modificaciones en la calle central, en la zona inmediata al altar, modificaciones que exasperaron a Don Antonio Ponz ${ }^{12}$. Fray Juan de la Cruz dice textualmente en su crónica ya citada, como Fray García de Loaysa «adornó la iglesia de retablo y reja» ${ }^{13}$.

El material de los sepulcros parece alabastro, junto con algunas piezas de jaspe rojo utilizado en contrapilastras, base de estatuas y medallones, lo que ya de entrada apunta a un maes-

\footnotetext{
${ }^{8}$ En los años finales del siglo xix, Don Juan Nepomuceno Peñalosa y Contreras, tio del último Marqués de Lozoya de quien llevaba su nombre, y Dña. Elena de la Quintana, compraron el arruinado edificio del convento de San Ginés y construyeron en él el actual colegio de la Compañía de María. La nueva fundación se inauguraba en el año 1900.

${ }^{9}$ Fernández y Sánchez, Ildefonso: Historia de Talavera de la Reina, Talavera, 1896.

${ }^{10}$ Redondo Cantera, Ma José: El sepulcro en España en el siglo xvi: Tipología e Iconografía, Ministerio de Cultura, Madrid, 1987.

1 Gómez Diaz, Rafael: «El arte anónimo de la iglesia de Sto. Domingo de Talavera», La Tribuna, Talavera, 8 de noviembre de 1998. Es una especie de carta que un fraile anónimo talaverano envía a un compañero suyo del convento dominico de Sto. Tomás de la Corte, en la segunda mital del siglo xviII, donde se le da una pormenorizada descripción del estado de la iglesia en ese momento, comparando la calidad y el tamaño de su construcción con la del convento madrileño.

${ }_{12}$ Ponz, Antonio: Viage de España, T. VII, Madrid, 1784, pág. 22.

13 Fray Juan de la Cruz, o. c., fol. 194.
} 

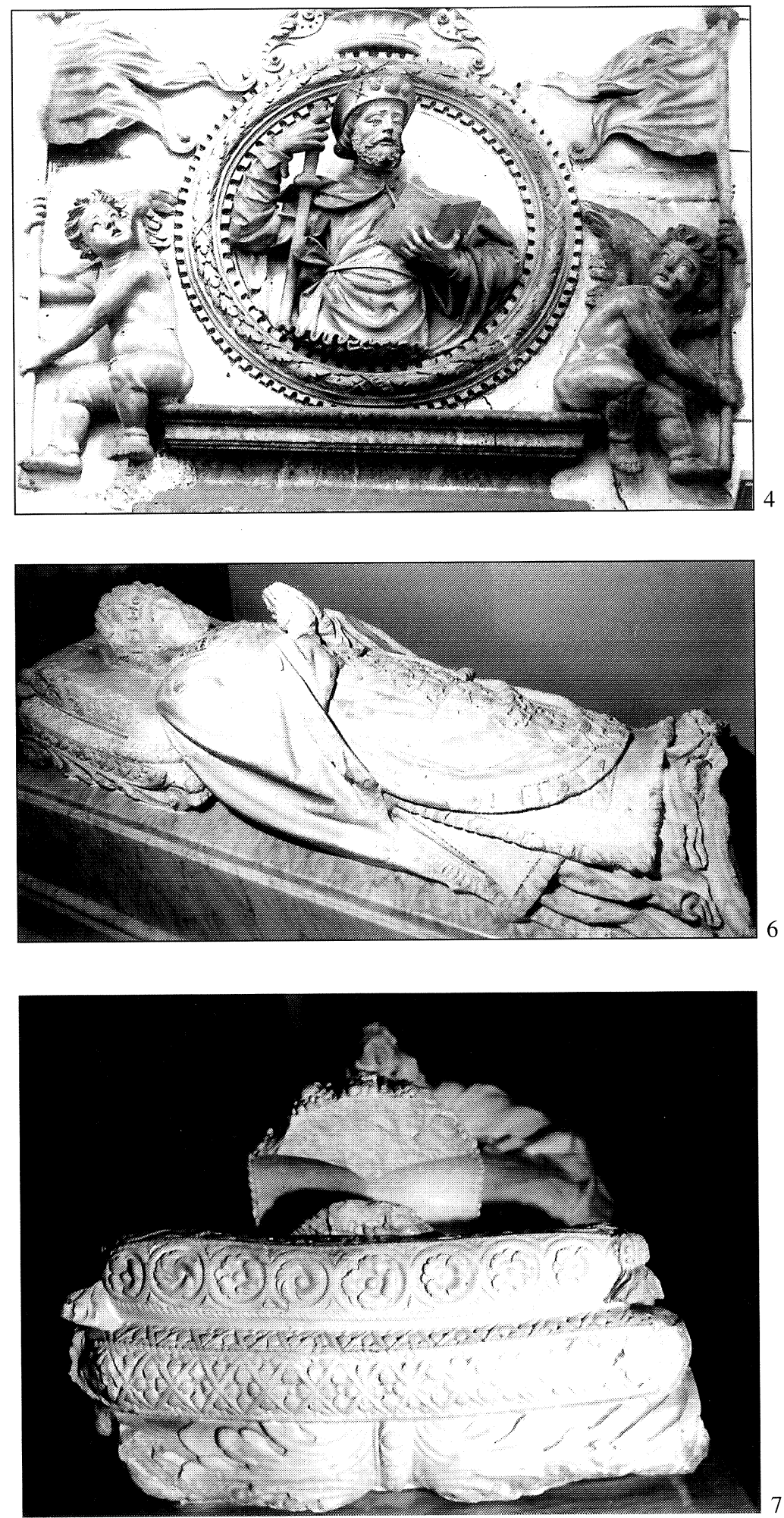

Fig. 4. Sepulcro de D. Pedro de Loaysa (detalle). Talavera de la Reina. Antigua iglesia de Dominicos.

Figs. 6 y 7. Sepulcro de Fray García de Loaysa (vista general y detalle). Talavera de la Reina. Antigua iglesia de Dominicos.

AEA, LXXVI, 2003, 303, pp. 267 a 276 
tro determinado, Felipe Bigarny, o tal vez será mejor que desde el primer momento, digamos a uno de sus talleres ${ }^{14}$. El nicho central, muy ancho y poco profundo, es un típico nicho rematado en venera con charnela hacia abajo cubierta de vegetación, tan frecuente en la zona burgalesa a partir de Diego de Siloe y que Felipe Bigarny utiliza en Toledo en el retablo de la Descensión de la catedral a partir de 1524. Dos esbeltos balaustres, del repertorio de Diego de Sagredo, flanquean la hornacina, casi idénticos a los que el escultor había ya utilizado en la calle central del retablo de la Capilla Real de Granada. Su delgadez da un carácter especialmente grácil al conjunto. El entablamento muestra un friso de cabecillas de serafines con las alas abiertas y ojos extremadamente rasgados. Los mismos serafines también adornan las enjutas del nicho central. En los extremos del entablamento, que avanzan en el espacio, los serafines del friso se sustituyen por sendos bustos de doncellas. Al sobresalir éste del plano de la hornacina da lugar a que la parte saliente se adorne con una serie de rosetas que Bigarny utiliza en otras varias arquitecturas. En los extremos de la cornisa se elevan dos esbeltos flameros $\mathrm{y}$, en la parte central, un podio de jaspe sostiene un tondo en cuyo interior vemos a una Virgen con el Niño, en el de la esposa, y la figura de Santiago, en el del marido. Flanqueando el tondo, sendos putti sentados en el podio elevan banderolas que flamean al viento y en el centro se eleva una especie de gran florón que remata en una cabecilla de serafín con las alas extendidas. Bajo la hornacina vemos un segundo entablamento que se adorna en el centro con bellísimas coronas de jugosa hojarasca y frutas que albergan en su interior los escudos familiares, tallados sobre cartelas de cueros recortados y rematados por un yelmo coronado del que pende sinuoso penacho vegetal, de sabor un tanto arcaizante, muy semejante al que el taller colocará en la portada del palacio de Peñaranda de Duero. Las coronas se apoyan en monstruosa carátula masculina la de la dama y en águila con las alas abiertas la del caballero. Sirviendo de nexo entre las coronas y los capiteles vemos ménsulas planas terminadas en roleos muy típicas en la decoración de todo el siglo xvi.

Hay un detalle original en el modo de plantear este sepulcro hornacina, la estructura de su diseño no llega hasta el suelo y las columnas abalaustradas, que lo flanquean se apoyan en un basamento, resuelto como un friso, que aparece sostenido por dos capiteles que quedan al aire sin columnas que les sirvan de sujeción. En otros sepulcros conocidos en los que ocurre esto mismo el friso o el balaustre aparecen sujetos por putti, que en ocasiones forman pareja, y lo más frecuente es que se sujete en ménsulas. La solución que aquí vemos parece típica, aunque no exclusiva, toledana. Aparece en la hornacina del «Quo Vadis» que remata el conjunto de la puerta de la capilla de San Juan Bautista en la catedral que, además, presenta un esquema arquitectónico muy semejante y cronologicamente está muy cercana en fecha ${ }^{15}$ y en la decoración de las zonas altas de las puertas del crucero.

En el tondo que remata el sepulcro de Dña. Catalina vemos un relieve de la Virgen sentada abrazando al Niño que aparece de pie apayado en una cabeza de angelillo, y otra cabecilla vemos apoyada bajo el brazo derecho de la Virgen. No parece figura de gran calidad y la figura de un Niño o de la Virgen apoyados sobre la cabeza de un angelillo es algo muy frecuente en todo el mundo burgalés y toledano cercano a Bigarny ${ }^{16}$.

Santiago apostol, de algo más de media figura, preside el tondo en el sepulcro de enfrente. Está representado como apostol, de ahí el libro abierto que, de modo muy elegante, porta

\footnotetext{
${ }^{14}$ Del Río de la Hoz, Isabel: El escultor Felipe Bigarny (h. 1470-1542), Junta de Castilla y Leon, Consejería de Educación y Cultura, 2001. Esta reciente obra, tesis doctoral de su autora, nos da una visión precisa y nueva de la obra de Felipe Bigarny y sus talleres.

${ }^{15}$ Chueca Goitia, Fernando: Arquitectura del Siglo xvI, Vol. XI de Ars Hispaniae, Ed. Plus-Ultra, Madrid, 1953.

${ }^{16}$ Nicolau Castro, Juan: «Dos relieves del círculo de Gregorio Pardo en la parroquia de Santa Leocadia y en el monasterio de Santa Clara de Toledo», Archivo Español de Arte, Nº 224, 1983, pp. 416-418.

$A E A$, LXXVI, 2003, 303, pp. 267 a 276
} 
en su mano izquierda, y como peregrino, como vemos por su sombrero con la venera santiaguista, el bordón que coge en su mano derecha y el hábito con manto de peregrino. Es posiblemente la figura más grata del conjunto y enlaza con el marco a través de unos pliegues menudos, casi caligráficos, que hemos visto en otras obras del taller de Bigarny como en la figura de la Templanza de una de las pilastras del crucero de la catedral de Burgos ${ }^{17}$. Salvando el estilo y la distancia, creemos ver el punto de partida de esta figura en el bellísimo Santiago de Gil de Siloe que adorna el retablo mayor de la Cartuja de Miraflores, para donde Bigarny trabaja en sus primeros años burgaleses ${ }^{18}$.

La figura orante de Dña. Catalina de Mendoza está arrodillada sobre un cojín con decoración que simula bordado. Cubre su cabeza con una toca fruncida y viste saya, con amplias mangas cerradas con lechuguilla, atada a la cintura con un ceñidero ${ }^{19}$. En la espalda, de manera más bien decorativa, porta un manto que cae en pliegues curvos y cubre por detrás la figura hasta ocultar enteramente los pies. Une las

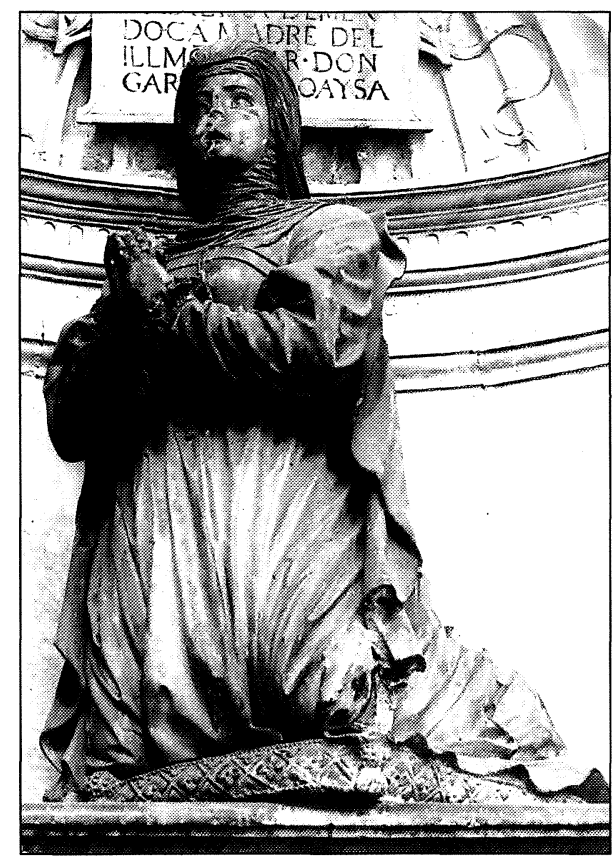

Fig. 5. Sepulcro de D. ${ }^{a}$ Catalina de Mendoza (detalle). Talavera de la Reina. Antigua Iglesia de Dominicos. manos en recogida oración y no muestra facciones individualizadoras, rostro alargado de óvalo muy redondeado con ligero prognatismo, nariz larga, hoy mutilada, y ojos grandes muy rasgados, es una repetición de otras figuras del conjunto y, en parte, recuerda el rostro de la Virgen de los sepulcros de Espeja que se realizan en fechas cercanas ${ }^{20}$. Son evidentes grandes analogías entre esta figura y la de la reina Leonor de Aragón, esposa de Juan I de Castilla, en el presbiterio de la capilla de Reyes Nuevos de la catedral de Toledo, obra que se pagaba en 1534 al maestre Jorge o Jorge Contreras ${ }^{21}$. En el centro de la venera que remata el nicho vemos el epitafio sobre una cartela con serpenteantes filacterias, la inscripción en el de la esposa dice asi, AQVI YAZE DONNA / CATALINA DE MEN / DOCA MADRE DEL / ILLMO. S. CAR. DON / GARCIA DE LOAYSA /, y en la del marido, AQVI YAZE PEDRO DE / LOAYSA PADRE DEL /ILLMO. S. CAR. DON GAR / CIA DE LOAYSA DELCONSEJO / DE LOS REYES CATÓLICOS. La fecha de su ejecución corresponde con toda seguridad a la cuarta década del siglo xvi. Su hijo, el Cardenal Loaysa, estando aun en Roma en febrero de 1533, conseguía licencia del papa Clemente VII para trasladar los restos de sus padres al nuevo convento y visitaba las obras de la iglesia en la Pascua de 1534. Los restos eran solemnemente trasladados desde otras iglesias de Talavera el 19 de abril de 1536, días antes de la consagración del templo que tenía lugar el 25 del mismo mes ${ }^{22}$.

En cuanto al estilo de estos cenotafios, como vamos viendo, todo nos lleva al entorno burgalés y toledano, lo que encaja plenamente dada la vinculación de la antigua villa de Talavera

\footnotetext{
17 Speranza, Fabio: «La Escalera Dorada de la Catedral de Burgos», Archivo Español de Arte,No 293, 2001 , pp. 19-44.

18 Del Río de la Hoz, Isabel, o.c.

19 Bernis, Carmen: Indumentaria española en tiempos de Carlos V, Instituto «Diego Velázquez», C.S.I.C.,Madrid 1962.

${ }^{20}$ Sánchez Cantón, F.J.: «Los sepulcros de Espeja», Archivo Español de Arte y Arqueología, T. IX, 1933, pp. 117-125.

${ }_{21}$ Pérez Sedano, Francisco: Datos documentales inéditos para la $H^{a}$ del Arte español (Notas del archivo de la Catedral de Toledo), Madrid, 1914, pág.58 y Zarco del Valle, Manuel: Datos documentales para la $H^{a}$ del Arte español. Documentos de la Catedral de Toledo. Madrid, 1916, T. I, p. 191.

${ }^{22}$ Gómez Gómez, José María, o.c.
} 
con la poderosa sede arzobispal de Toledo. Y ya hemos visto como nos lleva más concretamente al mundo de los Bigarny y al taller que se estableció en Toledo que, de manera precisa, nos ha desvelado la tesis de la Dra. Isabel del Río ${ }^{23}$. Elementos típicos de Bigarny, que aquí encontramos, ya los hemos ido desgranando a lo largo de su descripción, pero queremos destacar la utilización del color, de tradición borgoñona, a base del empleo de alabastro y jaspe de las canteras de Espeja en Soria, que su taller con tanta frecuencia combina, el tipo de balaustre repetido en la obra de Sagredo, que en tantas obras del taller del escultor borgoñón se repite, la venera con charnela hacia abajo y adornada con decoración vegetal que Bigarny inaugura en Toledo, las figuras de los tondos de tradición burgalesa y el esquema del conjunto que sigue, casi al pie de la letra, aunque con menor monumentalidad, el de los sepulcros de los Avellaneda del monasterio de San Jerónimo de Espeja. Sin embargo la ejecución del detalle parece flojo y ello logicamente nos lleva al taller y a ese cúmulo de escultores de los primeros decenios del siglo xvi que poblaban los talleres de Burgos y Toledo y sobre los que aun queda campo por investigar.

Estos sepulcros sufrieron un gran deterioro a lo largo del siglo xIx, perdiéndose varias piezas de ellos. Fueron restaurados en los ultimos años del siglo por iniciativa de Dña. Elena de la Quintana, viuda ya de Don Juan Nepomuceno Peñalosa y Contreras. De la restauración se encargó un ceramista o escultor de apellido Perales, que debió ser Juan José Perales amigo de Juan Ruiz de Luna Rojas quien copiaría en repetidas ocasiones estos sepulcros convirtiéndolos en espléndidos retablos de cerámica ${ }^{24}$.

Más complejo resulta a primera vista el estudio del sepulcro del Cardenal sobre todo porque de él sólo nos ha llegado su estatua yacente y ésta en malas condiciones de conservación. Sobre él tenemos algunos datos, escasos y poco esclarecedores, que aparecen en los pocos documentos localizados, en crónicas de la orden dominica, en antiguas historias de Talavera y en el «Viaje de España» de Don Antonio Ponz. Resumiendo todo ello tenemos que el Libro Becerro del monasterio del Archivo Histórico Nacional de Madrid dice que abierto su testamento en 1546, poco después de morir, en él manda «que la Capilla Mayor de la iglesia de este convento de San Ginés sea entierro de su cuerpo y los guesos de sus padres y del de su sobrino Alvaro de Loaysa y de sus sucesores» ${ }^{25}$. Este sobrino comenta a su vez, el 9 de febrero de 1553, «que ya por este tiempo está su cuerpo enterrado en la Capilla Mayor» ${ }^{26}$. El padre Fray Juan de la Cruz en su «Crónica de la Orden de Predicadores...» dice textualmente que el cuerpo de Fray Garcia de Loaysa fue traído a Talavera desde Madrid, donde murió, a su convento de San Ginés en que tenía elegida sepultura, donde se le puso en «un sepulcro azzas rico y bien labrado de jaspe y alabastro» ${ }^{27}$. Por su parte distintas historias manuscritas de Talavera vienen a decir más o menos lo mismo, dando la sensación de haberse copiado unas a otras. El historiador Francisco de Soto dice textualmente, «el Cardenal está enterrado en la bóveda de la Capilla Mayor de esta iglesia a donde en medio de ella, está un sepulcro de jaspe muy bien labrado, y encima su bulto de alabastro magestuoso, y, verdaderamente de Señor; y en el frente del sepulcro que mira al altar mayor, está una tabla del mismo jaspe con su epitafio» ${ }^{28}$. En

\footnotetext{
${ }^{23}$ Del Río de la Hoz, Isabel, o.c.

${ }^{24}$ Debo esta noticia a la amabilidad de Rafael Gómez Díaz, archivero del Ayuntamiento de Talavera de la Reina. Ver también Hurley Molina, María Isabel: Talavera y los Ruiz de Luna, I.P.I.E.T., Diputación Provincial de Toledo.

${ }^{25}$ El testamento de Fray García de Loaisa se otorgó en Valladolid el 12 de septiembre de 1545 ante el escribano de la ciudad Zebrián Pérez. En el convento de Talavera se guardaba copia de este testamento, sacado del original, por el escribano de Talavera Garcí Fernán. Desgraciadamente los protocolos de estos dos escribanos no se conservan.

26 Libro Becerro del Convento de San Ginés..., fol. 16.

27 Fray Juan de la Cruz, o.c., fol. 194.

${ }^{28}$ Soto, Francisco de: $H^{a}$ de la antiquísima Ciudad y Colonia Romana Elbora de la Carpetania hoy Talavera de la Reina, 1765, Archivo Municipal de Talavera de la Reina, pág. 129.
}

AEA, LXXVI, 2003, 303, pp. 267 a 276 
el manuscrito del siglo xviII de la Biblioteca Nacional donde se describe el estado de la iglesia en ese momento y se comenta cómo el sepulcro del Cardenal se encontraba, ya entonces, en el muro de la epístola, enfrente de la puerta de la sacristía, «elevado como una vara del suelo», traido allí del centro de la capilla mayor donde estuvo cercado por una verja de hierro y añade el anónimo informador «y porque estorbaba lo arrimaron a la pared». Al referirse este manuscrito a los sepulcros de los padres en el presbiterio dice textualmente «están las esculturas colocadas mirando hacia el altar mayor como está Hernán Cortés en la Merced de esa Corte» ${ }^{29}$, refiriendose erroneamente a la escultura de Don Fernando Cortés y a su esposa Dña. Mencía de la Cerda, nietos del gran conquistador . Más datos aporta don Antonio Ponz en su «Viaje de España» donde escribe que vio tres magníficos sepulcros de mármol, en la capilla mayor los de los padres, y el de Fray García de Loaysa arrimado a la pared del múro de la epístola, «y consiste en una urna delicadamente trabajada, y sobre ella una estatua tendida, con hábito pontifical, y executada diestramente» ${ }^{30}$. Para obtener algunos nuevos datos hay que esperar a la publicación de la Historia de Talavera de don Ildefonso Fernández y Sánchez en el año $1896{ }^{31}$. En ella, el historiador cuenta cómo el mausoleo del Cardenal fue profanado por las tropas francesas y, terminada la guerra, lo colocaron en la capilla de la Santa Cruz del templo. Tras la desamortización se tabicó la capilla para que no se profanase el mausoleo. Con posterioridad Dña. Elena de la Quintana entregó la estatua al erudito talaverano Don Luis Jiménez de la Llave que intentó restaurarla con ayuda del Ayuntamiento. Fracasado el intento, fue llevada a la parroquia de San Salvador de los Caballeros, a la antigua capilla de la Virgen de las Nieves, donde Don Luis pretendía hacer por esos años algo muy de moda en el siglo XIX, un pequeño panteón de hombres ilustres. Desde aquí fue devuelta a su antiguo emplazamiento, hace muy pocos años.

Resumiendo todos estos datos, un tanto farragosos, podemos sostener que el lecho del sepulcro debió consistir en una gran pieza piramidal de jaspe que con su tono rojizo destacaría la blancura del marmol empleado en la figura yacente del Cardenal. Esta solución fue impuesta por Bigarny y su entorno en las tumbas de los Condestables, Don Pedro Fernández de Velasco y Dña. Mencía de Mendoza, en su capilla de la catedral de Burgos, en el mausoleo de Fray Alonso de Burgos en la capilla de San Gregorio de Valladolid, destruido por las tropas francesas y punto de partida de un tipo de sepulcro ideado por maestre Bigarny, como el de Don Pedro González Manso, obispo de Osma, en el monasterio burgalés de San Salvador de Oña, el del obispo Don Pedro Alvarez Acosta en el monasterio de Sancti Spiritus de Aranda de Duero o el de Don Pedro de La Gasca, obispo de Palencia y Sigüenza, en la iglesia de la Magdalena de Valladolid, tallado ya en 1571 por Esteban Jordán, pero siguiendo expresamente las indicaciones de tomar por modelo el del Colegio de San Gregorio ${ }^{32}$. Todos estos personajes, por sus puestos y dignidades, estuvieron en estrecho contacto entre sí, presidieron las mismas sedes y varios pertenecieron a la misma orden religiosa. Por otra parte, todos, además, pasaron años de su vida en Valladolid, donde vieron y admiraron el mausoleo de Fray Alonso de Burgos. Recentísimamente hemos localizado un prueba definitiva que avala esta opinión. En una última visita al convento, hoy colegio de la Compañía de María, las monjas amablemente nos mostraron una gran losa de jaspe rojo que, desde tiempo inmemorial, se viene utilizando como mesa en la huerta del colegio. Es una gran pieza delicadamente tallada que fue, sin duda la losa que sostendría la estatua del Cardenal. Sí parecen definitivamente perdidas las otras piezas que formarían la pirámide del lecho.

\footnotetext{
${ }^{29}$ Gómez Diaz, Rafael: o.c.

30 Ponz, Antonio, o.c., T.VII, p. 22.

31 Férnandez y Sánchez, Ildefonso, o.c.

${ }^{32}$ Del Río y de la Hoz, Isabel, o.c.
} 
La estatua yacente de Fray García de Loaisa nos ha llegado en un lamentable estado de deterioro que no parece se deba unicamente a la proximidad de un horno de alfar como dice, en su Historia, Don Ildefonso Fernández. El Cardenal aparece vestido de pontifical con alba, palio y dalmática riquísimamente adornada de pedrería hasta rayar el cansancio por lo prolijo. En las manos lleva guantes y sobre ellos adorna algunos dedos con anillos. La cabeza, con el rostro mutilado e irreconocible, ha sido ultimamente sometida a una drástica restauración, y lleva sobre ella la mitra tan fatigosamente decorada como el resto de las vestiduras, bajo ella destaca el cabello corto, peinado a diminutos mechoncillos que circundan la cabeza. Interesante por lo que pueda ayudar a situarnos es la decoración de los cojines y alguna otra curiosa pieza que eleva su cabeza. Sirviendo como lazo de unión entre los cojines y el lecho hay una pieza de tipo vegetal rematada en roleos que recuerda elementos burgaleses de la Escalera Dorada y que Bigarny ya utilizó parecidos en la decoración que enmarca los medallones del lecho sepulcral de don Gonzalo de Lerma, en la capilla de la Presentación de la catedral de Burgos. Sobre esta pieza apoyan dos cojines sobre los que reposa la cabeza del yacente, adornados sus bordes con decoración repetida en obras de Bigarny y del entorno toledano. Sobre la superficie del cojín superior se ha tallado una decoración muy fina a base de volutas estriadas terminadas en roleos de gran tradición bigarnyana. Por último, a los pies de la escultura y apoyada en ellos, hay una venera idéntica a la que remata la hornacina de los padres en la que vemos también una cartela semejante con el siguiente epitafio: ILLVSTRISSIM. HIC. JACET. GARSIAS. A. LOAYS. HISPL. CARD. SVPREMI. INQVISITIONIS. SENT. NEC. NON. REGII. INDIAZ. CONSILII. PRESIDES. GLIS. Q. HISPANIE. COMISSARI. OBIIT. ANNO. DO. M.D.XLVI. El ritmo intensamente movido de los pliegues del alba en esta zona de los pies recuerda, en su sinuoso juego de curvas y contracurvas, la parte baja de la figura de Santiago que culmina el sepulcro de Don Pedro de Loaysa.

¿Cuándo debemos fechar esta escultura?, casi con seguridad en fecha muy cercana a la muerte del Cardenal que sucede en el mes de abril de 1546, unos diez años depués de cuando, presumiblemente, se debieron tallar los sepulcros de los padres. Como hemos ido viendo, su vinculación al estilo de Bigarny y a lo toledano contemporáneo es grande. El padre, Felipe Bigarny, había ya muerto en estas fechas, pero el hijo, Gregorio Bigarny o Pardo, mantenía su taller en Toledo y se hacía cargo de obras emprendidas por su padre y es ahí donde creemos deba situarse el sepulcro talaverano del Cardenal. Una prueba más de como la influencia de Bigarny llegaba a Talavera la tenemos en el documento que Fernando Marías publicó, en el que se documenta la existencia, en el monasterio de madres benitas de la ciudad, de una sillería de coro semejante a la de San Clemente de Toledo que había realizado Felipe Bigarny en $1536^{33}$.

Hoy, tras la remodelación de la iglesia, la escultura descansa sobre un plinto de marmol blanco colocado bajo una hornacina rematada en arco gótico en el muro de la epístola, en un lugar muy cercano al que tuvo en el siglo XviII.

\footnotetext{
${ }^{33}$ Marías, Fernando: «Notas sobre Felipe Bigarny: Toledo y La Espeja», Boletín del Seminario de Arte y Arqueología T. XLVIII, 1981, pp. 425-429.
}

AEA, LXXVI, 2003, 303, pp. 267 a 276 